\title{
A comparison of cloud and boundary layer variables in the ECMWF forecast model with observations at Surface Heat Budget of the Arctic Ocean (SHEBA) ice camp
}

\author{
J. A. Beesley, ${ }^{1,2}$ C. S. Bretherton, ${ }^{3}$ C. Jakob, ${ }^{4}$ E. L Andreas,${ }^{5}$ J. M. Intrieri, ${ }^{6}$ \\ and T. A. Uttal ${ }^{6}$
}

\begin{abstract}
Cloud and boundary layer variables from the European Centre for MediumRange Weather Forecasts (ECMWF) forecast model were compared with measurements made from surface instruments and from upward looking $8 \mathrm{~mm}$ wavelength radar and lidar at the Surface Heat Budget of the Arctic Ocean (SHEBA) ice camp during November and December of 1997. The precipitation accumulation, near-surface winds, and surface downward longwave irradiance predicted by the model were in good agreement with SHEBA observations during this period. However, surface downward longwave irradiance was underestimated by $10 \mathrm{~W} \mathrm{~m}^{-2}$ on average when low clouds were present in the model and observations. The model demonstrated considerable skill in predicting the occurrence and vertical extent of cloudiness over SHEBA, with some tendency to overestimate the frequency of clouds below $1 \mathrm{~km}$. A synthetic radar reflectivity estimated from the ECMWF model variables was compared with $8 \mathrm{~mm}$ wavelength radar measurements. The two were broadly consistent only if the assumed snowflake size distribution over SHEBA had a smaller proportion of large flakes than was found in previous studies at lower latitudes. The ECMWF model assumes a temperaturedependent partitioning of cloud condensate between water and ice. Lidar depolarization measurements at SHEBA indicate that both liquid and ice phase clouds occurred over a wide range of temperatures throughout the winter season, with liquid occurring at temperatures as low as $239 \mathrm{~K}$. A much larger fraction of liquid water clouds was observed than the ECMWF model predicted. The largest discrepancies between the ECMWF model and the observations were in surface temperature (up to $15 \mathrm{~K}$ ) and turbulent sensible heat fluxes (up to $60 \mathrm{~W} \mathrm{~m}^{-2}$ ). These appear to be due at least partially to the ECMWF sea ice model, which did not allow surface temperatures to respond nearly as rapidly to changing atmospheric conditions as was observed.
\end{abstract}

\section{Introduction}

The Arctic planetary boundary layer poses a unique challenge for general circulation models (GCMs) used in climate studies and weather forecasting owing to its persistent stable stratification and the important role of ice phase microphysical processes in boundary layer cloud formation and evolution. For example, the GCM intercomparison study of Tao et al. [1996] found large errors in the predicted mean annual cycles of surface temperature and cloudiness in the Arctic. In the effort to improve GCM performance in the Arctic the Surface Heat Budget of the Arctic Ocean Experiment (SHEBA) collected data at a drifting sea ice camp located north of Alaska

\footnotetext{
${ }^{1}$ National Ice Center, Washington, D.C.

${ }^{2}$ Temporarily at Department of Atmospheric Sciences, University of Illinois, Urbana.

${ }^{3}$ Department of Atmospheric Sciences, University of Washington, Seattle.

${ }^{4}$ European Centre for Medium-Range Forecasts, Reading, England.

${ }^{5}$ U.S. Army Cold Regions Research and Engineering Laboratory, Hanover, New Hampshire.

${ }^{6}$ Environmental Technology Laboratory, NOAA, Boulder, Colorado.

Copyright 2000 by the American Geophysical Union.

Paper number 2000JD900079.

0148-0227/00/2000JD900079\$09.00
}

between $74^{\circ}$ and $81^{\circ} \mathrm{N}$ for a full year beginning in October 1997 [Perovich et al., 1999]. The measurements of the atmosphere, sea ice, and upper ocean will provide a rigorous observational test of single-column models over the Arctic sea ice [e.g., Pinto et al., 1999]. The atmospheric component of a single-column model requires specification of large-scale vertical motion and advective tendencies of temperature and moisture. It was boldly decided that it was impractical to continuously measure these tendencies; instead, numerical weather prediction models would be relied on for specifying them. To aid this process, twice-daily soundings and 6-hourly surface observations from the SHEBA ice station were communicated via the Global Telecommunications System to the major numerical weather prediction centers. One participating forecast center was the European Centre for Medium-Range Weather Forecasts (ECMWF). The ECMWF model has a package of physical parameterizations that are generally at least as sophisticated as most GCMs, 31 vertical levels with a lowest grid level of $\sim 30 \mathrm{~m}$, a vertical grid spacing of $300 \mathrm{~m}$ near the surface that gradually increases with height, and T213 spectral resolution (roughly equivalent to a $60 \mathrm{~km}$ grid spacing) in the horizontal. In this paper, we compare short-range predictions of cloud and boundary layer variables by the operational ECMWF model with surface-based measurements made in the central Arctic during November and December of 1997. The surface condi- 

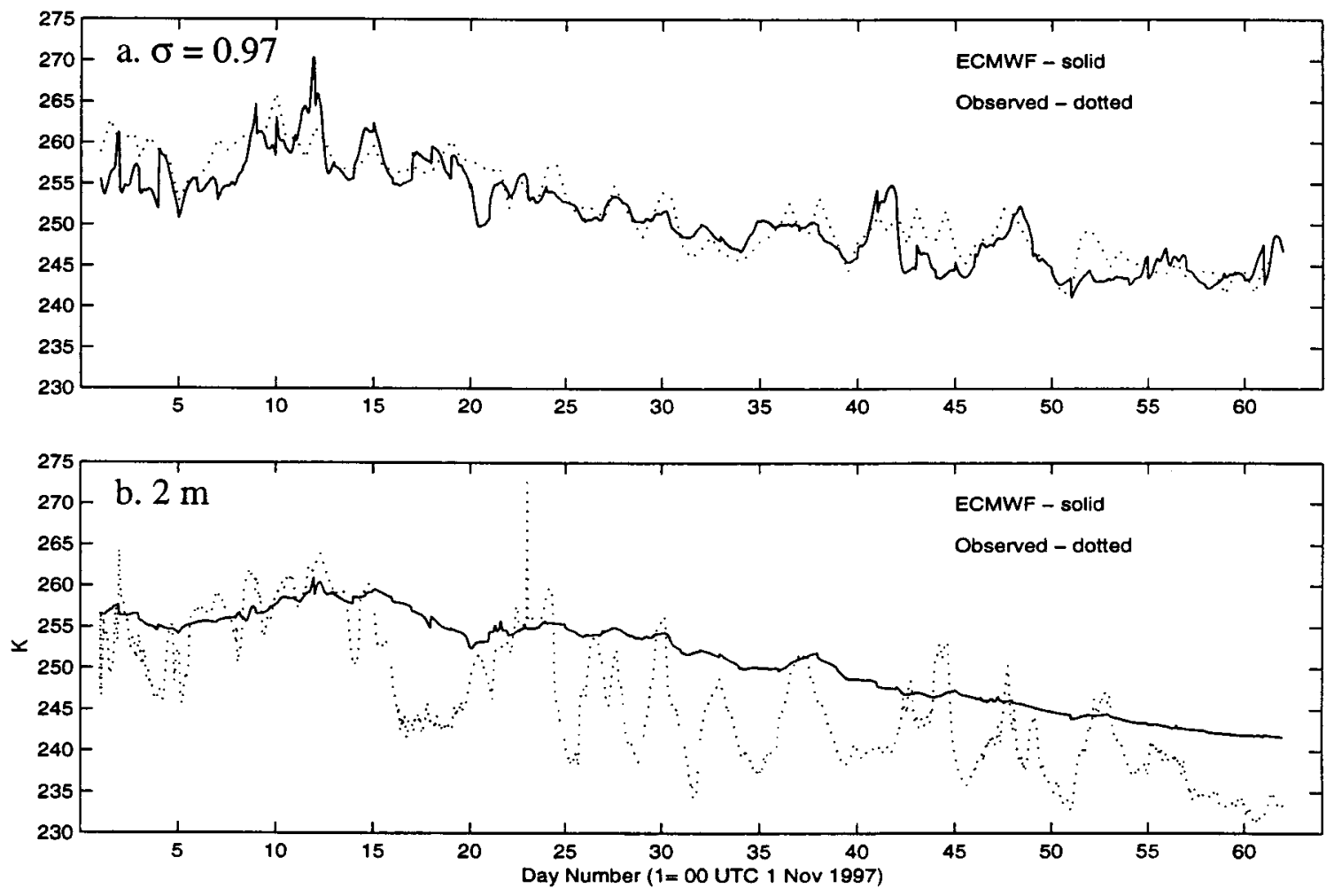

Figure 1. A comparison of measured and modeled air temperature at the Surface Heat Budget of the Arctic Ocean (SHEBA) ice camp in November and December 1997. (a) The temperature at the second lowest model level ( $\sim 300 \mathrm{~m})$. Observations are from twice-daily atmospheric soundings. (b) The $2 \mathrm{~m}$ air temperature. These observations are hourly averages.

tions in the area surrounding the SHEBA camp were fairly homogeneous due to the virtual absence of openings in the ice cover during this period. Hourly averages of wind, temperature, and humidity at the main camp were within instrument error of those at autonomous measurement sites up to $10 \mathrm{~km}$ away. Hence point measurements of most boundary layer quantities at the SHEBA site should be representative of the area average on the scale of an ECMWF model grid box.

The ECMWF operational forecast model assimilated wind, temperature, humidity, and height at $\sim 15$ standard pressure levels from atmospheric soundings obtained at SHEBA. Surface pressure was the only near-surface variable assimilated into the model. Approximately $85 \%$ of the atmospheric soundings taken at SHEBA were used. A variety of special diagnostic quantities were saved hourly for the model column nearest the moving ice camp. Since many model variables are subject to initialization transients and the model is run only once daily, the diagnostics were based on hours $12-35$ of each forecast. The assimilation was quite successful; above the boundary layer, there was close agreement of the time-varying model temperature, moisture, and wind profiles with the soundings. The variables examined in this study are not assimilated but are the product of the model's physical parameterizations, which we expect to perform as well as possible due to the accuracy of the assimilated variables. Although we still expect some errors in the timing and intensity of synoptic-scale atmospheric motions and advection, our comparison of forecasted and analyzed pressure-height fields (not shown) suggests that these errors do not significantly affect our conclusions. Also, the time series presented in this paper suggest that the timing of fronts in the model was fairly accurate. Above the boundary layer, temperatures during November and December varied from 250 to $270 \mathrm{~K}$, while near the surface, temperatures varied from 240 to $265 \mathrm{~K}$. A near-surface temperature inversion was present for $>90 \%$ of the period. Hence our comparison can be thought of as a test of how well the model's physical parameterizations can represent the stable boundary layer and the cloud distribution in a variety of subfreezing conditions, given a nearly correct thermodynamic state and advective forcing.

\section{Surface Variables}

The ECMWF model variables were compared with hourly average measurements of $2 \mathrm{~m}$ temperature, $2 \mathrm{~m}$ specific humidity, $10 \mathrm{~m}$ wind speed, sensible heat flux (using eddy correlation based on sonic anemometers mounted $\sim 2 \mathrm{~m}$ above ground level), and downward radiative fluxes (from Eppley broadband solar and infrared radiometers). The atmospheric surface flux measurement program at SHEBA is described in greater detail by Andreas et al. [1999]. Daily precipitation gauge measurements, provided by R. Moritz, and weekly snow depth measurements, from D. Perovich, were compared to surface precipitation in the model.

\subsection{Surface Weather Variables}

In the free troposphere the modeled and observed temperatures were usually less than 1 or $2 \mathrm{~K}$ apart. Figure 1a shows that as little as $300 \mathrm{~m}$ above the ice surface, model tempera- 

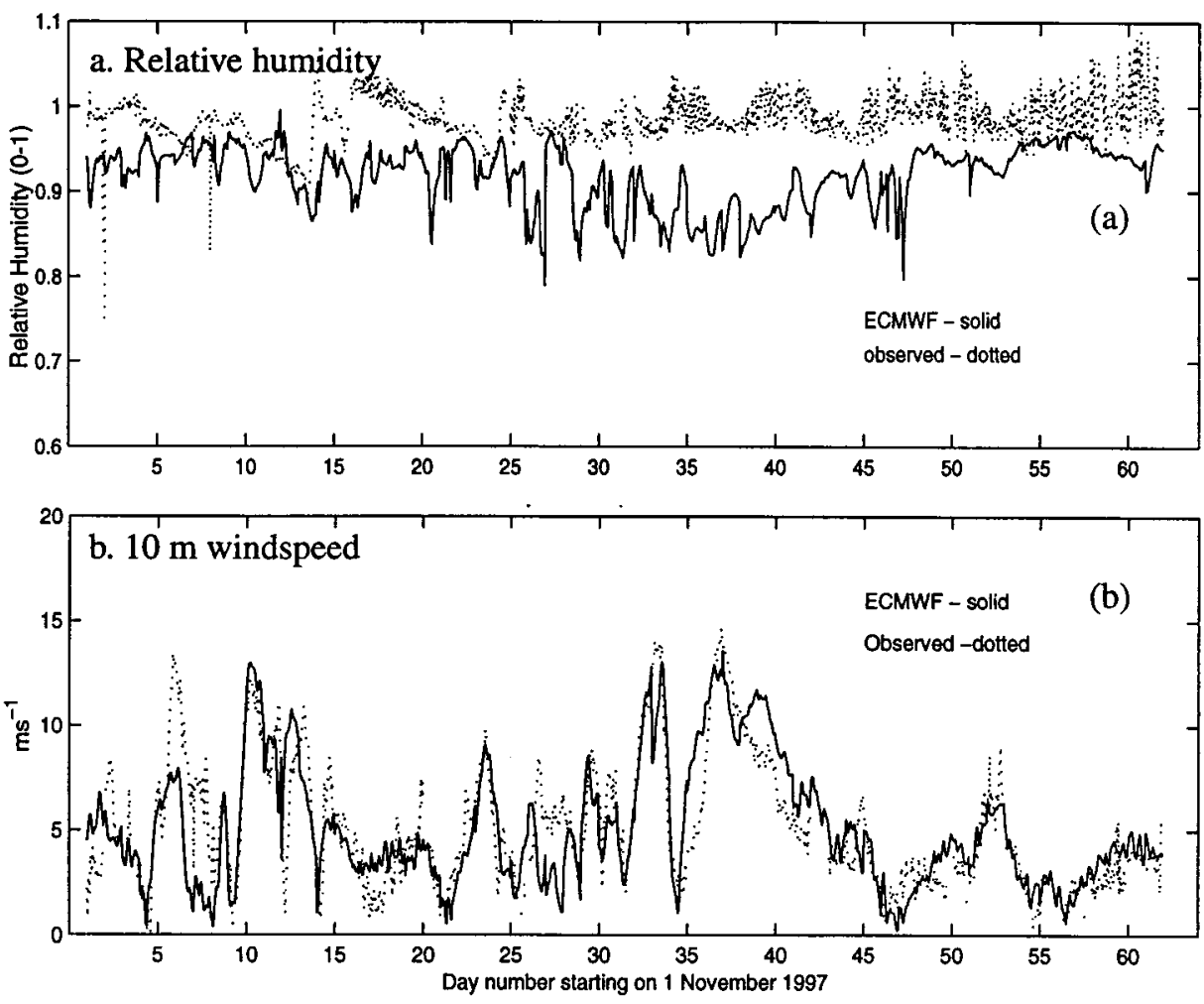

Figure 2. Measured and modeled values of (a) the $2 \mathrm{~m}$ relative humidity with respect to ice and (b) the $10 \mathrm{~m}$ wind speed at the SHEBA ice camp. Observed data series are hourly averages.

tures remained within $5 \mathrm{~K}$ of observations during November and December 1997. However, Figure 1b indicates large differences in the $2 \mathrm{~m}$ temperatures between the model and the observations that were similar to the differences in the respective skin temperatures. The model strongly underestimated $2 \mathrm{~m}$ temperature fluctuations and had a notable high bias during cold periods. Since the $2 \mathrm{~m}$ temperature was within $1 \mathrm{~K}$ of the skin temperature in both model and observations (not shown), this suggests a problem in the model surface energy budget. We found a likely culprit in the sea ice model, which treated the sea ice as snow-free isothermal slab of $2.5 \mathrm{~m}$ thickness whose temperature changes according to an energy balance equation. The large heat capacity of the sea ice strongly damped high-frequency surface temperature fluctuations. The sea ice near the SHEBA site was $1.6-2 \mathrm{~m}$ in thickness and was overlaid by $\sim 10-20 \mathrm{~cm}$ of snow during the period of interest, and it did not respond at all like an isothermal slab owing to its low heat conductivity. As a result of the current study, ECMWF is planning to implement a multilayer ice model to correct this deficiency.

The $2 \mathrm{~m}$ relative humidity measured at SHEBA was very close to (and often exceeded) $100 \%$ saturation with respect to ice for the whole period (Figure $2 \mathrm{a}$ ). The modeled $2 \mathrm{~m}$ relative humidity (Figure $2 \mathrm{a}$ ) was $\sim 6 \%$ lower than the observations on average and considerably more variable. Errors in specific humidity (not shown) were considerably larger than those in relative humidity and were qualitatively similar to errors in temperature because of the temperature-dependence of specific humidity.

The $10 \mathrm{~m}$ wind speed in the ECMWF model agreed well with observations (Figure 2b). The daily fluctuations in wind direction in the ECMWF model also were consistent with observations (not shown). The general agreement between the
ECMWF model and observed $10 \mathrm{~m}$ winds may partly reflect the initialization of the model with the daily atmospheric soundings but also suggests that the model is simulating well the synoptic-scale dynamics over SHEBA.

The cumulative precipitation reaching the surface in the ECMWF model was compared with measurements at $\sim 100$ stakes along a $500 \mathrm{~m}$ line near the SHEBA site. The average net accumulation (precipitation minus sublimation) along the snow line was $\sim 10 \mathrm{~cm}$ during November and December. This is equivalent to $30-40 \mathrm{~mm}$ of liquid water since the density of the snow layer at SHEBA was in the range of $0.3-0.4 \mathrm{~g} \mathrm{~cm}^{-3}$ (D. Perovich, Cold Regions Research and Engineering Laboratory, personal communication, 1998). The cumulative surface precipitation in the model ( $29.5 \mathrm{~mm}$ water equivalent) is fairly close to the estimated water content of snow accumulation at SHEBA. Rain, which accounted for 5\% of the model precipitation during this period, was mixed with the snowfall on days $12,15,24$, and 27 , when the temperatures aloft exceeded $\sim 265 \mathrm{~K}$. The precipitation at these times was reported as snow by surface meteorological observers at SHEBA. In fact, there were no references to rain or drizzle in the surface weather reports during November and December 1997. Possible reasons for rain reaching the surface in the model are that it should not have formed in the first place or that the evaporation of rainfall was underestimated.

To evaluate the timing of precipitation events in the ECMWF model, we compared the modeled daily surface accumulation with daily measurements at the SHEBA precipitation gauge (Figure 3). These uncalibrated measurements appear to suffer from severe undercatch. The sum of the daily precipitation gauge measurements during November and December 1997 was $9.5 \mathrm{~mm}$ water equivalent, while the snow stakes (a 


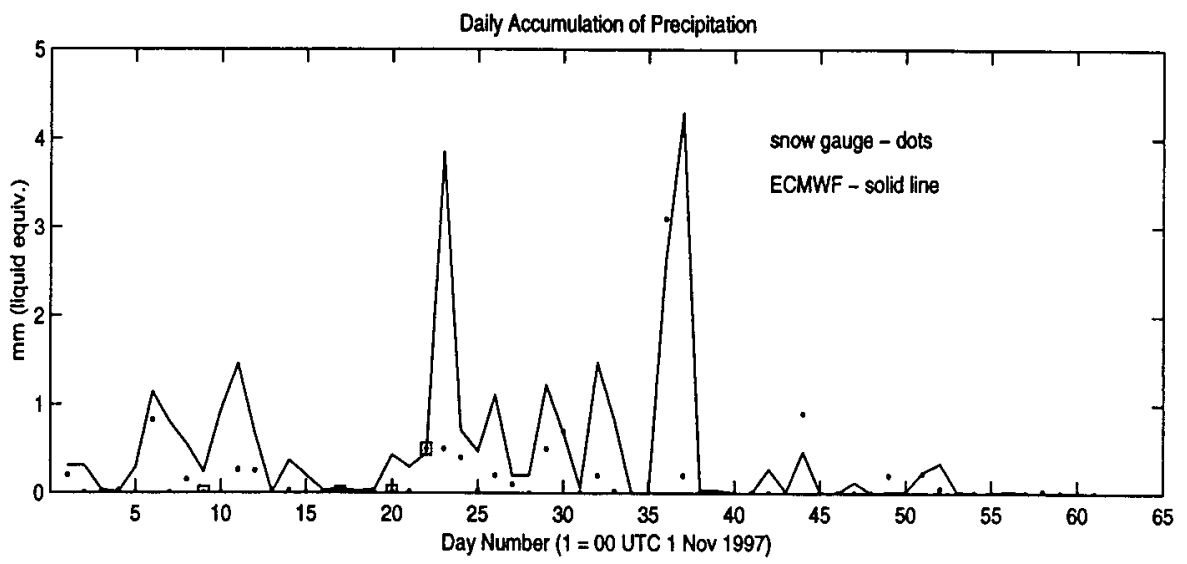

Figure 3. Daily surface precipitation accumulation in the ECMWF model and measured at the SHEBA ice camp. Snow gauge accumulations, measured near the end of each day (UTC), were provided by R. Moritz. If the accumulation measurement was missed (indicated by squares), the accumulation measured the following day is divided equally between the 2 days. During the November/December 1997 period, the precipitation gauge collected approximately a third of the actual snowfall at the SHEBA site (see text).

direct cumulative measurement) imply 30-40 mm water equivalent. Hence the daily measurements are trustworthy mainly as an indicator of whether snow fell on a given day. The model correctly predicted the presence or absence of measurable accumulations on $76 \%$ of the days. This is consistent with our finding in section 3 that the model precipitation fluxes are closely associated with observed peaks in radar reflectivity, which are indicative of precipitation.
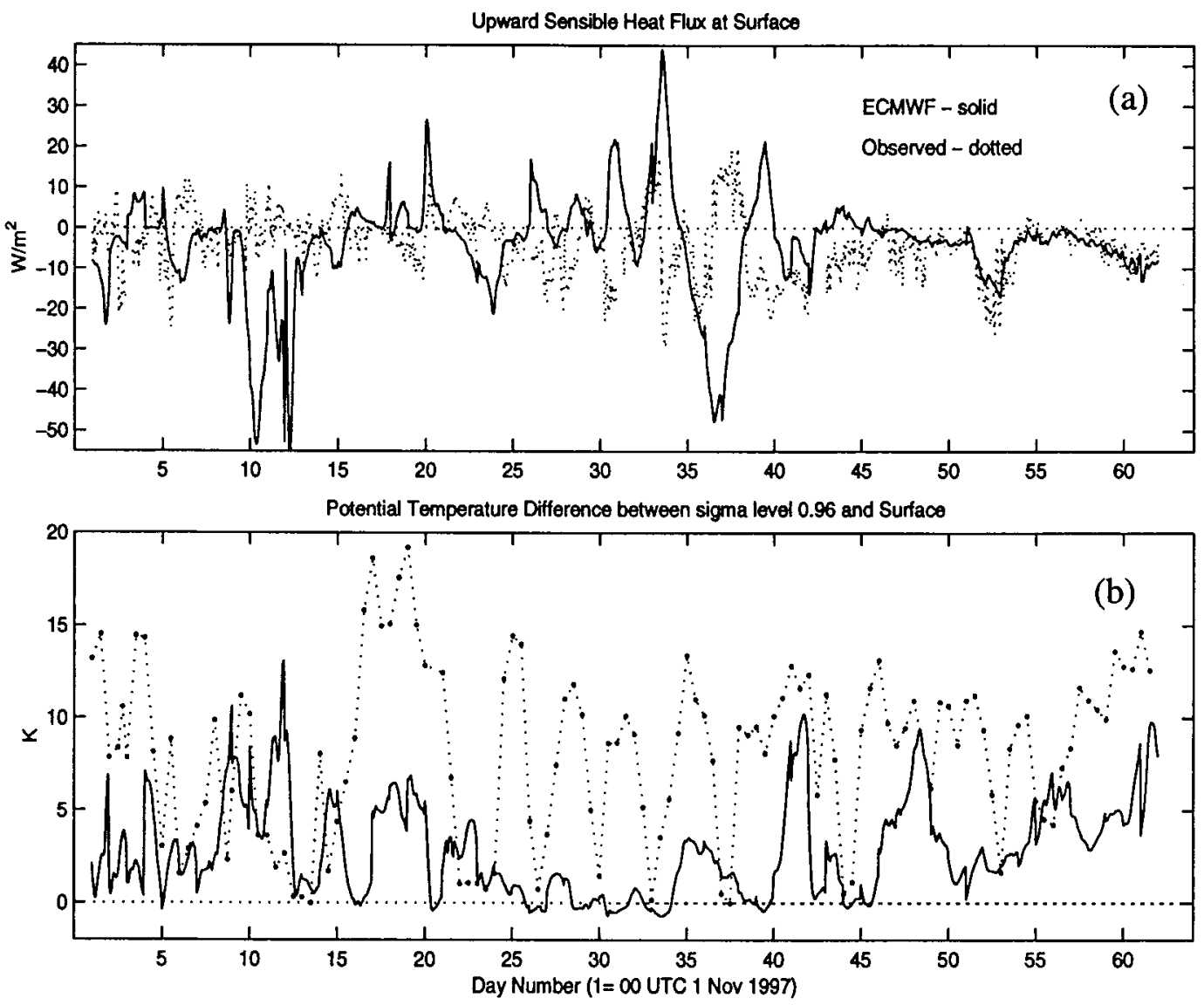

Figure 4. Measured and modeled upward sensible heat flux and stratification at the SHEBA. Sensible heat flux observations in Figure 4a are hourly averages computed using the eddy correlation method. Stratification (Figure 4b) is defined here as the difference in potential temperature between the height of the second lowest model level and $2 \mathrm{~m}$, using the same data as in Figure 1. 


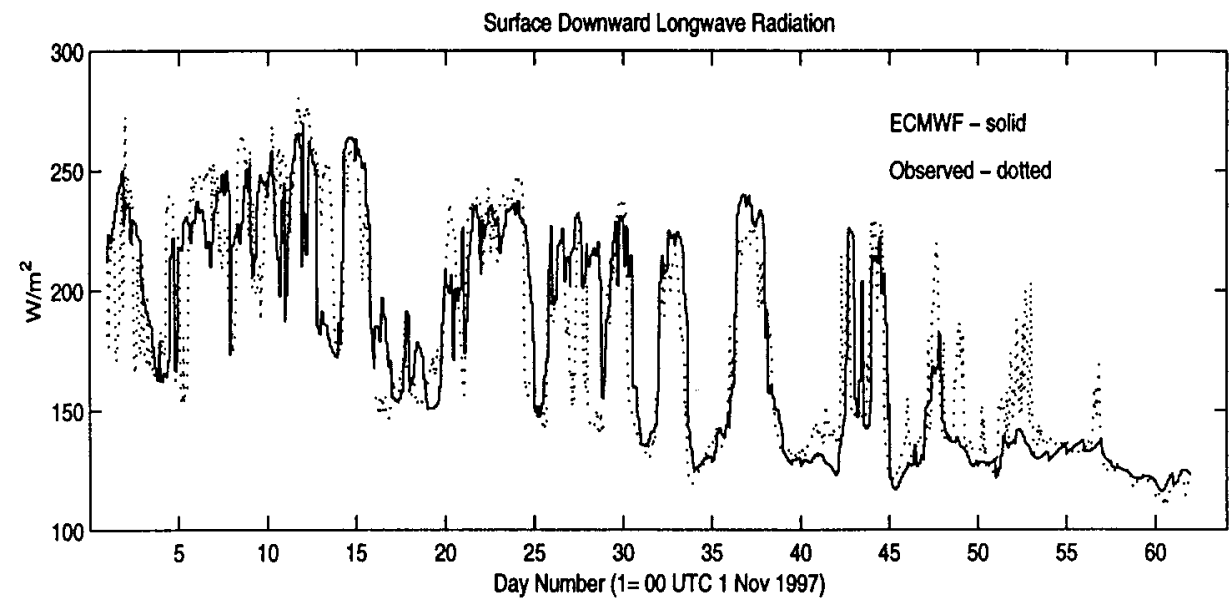

Figure 5. Measured and modeled surface downward longwave irradiance at the SHEBA ice camp in November and December 1997.

\subsection{Surface Energy Fluxes}

The average upward sensible heat flux in the ECMWF model during November and December was $-4.3 \mathrm{~W} \mathrm{~m}^{-2}$, which is surprisingly close to the observed average of $-4.0 \mathrm{~W}$ $\mathrm{m}^{-2}$, especially given the model's warm bias in surface temperature. On a daily timescale, however, the agreement between the model and observations was poor except for the last 12 days of the period (Figure 4). It is intriguing that this last 12 day period coincided with a change in the ECMWF model physics package on December 16, 1997, but the model changes are unlikely to have had a significant effect on the Arctic. It is noted that the ECMWF model does not account for the presence of openings (leads) in its sea ice model. Maykut [1978] has shown that large-scale turbulent fluxes of latent and sensible heat can be dominated by leads occupying a very small fraction $(1-2 \%)$ of the area, especially when air temperatures are well below freezing. This omission should not affect our comparison with measurements from the meteorological tower at SHEBA since there were no leads in the area during November and December 1997. We would expect the ECMWF model to underestimate upward latent and sensible heat fluxes in regions with $>1 \%$ open water when the air temperature is significantly below freezing.

The most prominent errors in the surface sensible heat flux in the model were two downward spikes centered at days 10-12 and 36-37 and three upward spikes on days 31, 33, and 39. The accuracy of the modeled near-surface winds does not appear to be the cause of these errors (see Figure 2b). A factor contributing to these errors was the coupling of large surface temperature biases to a temperature profile in the free atmosphere that (owing to assimilation of observed soundings) remained fairly accurate. In particular, erroneous upward spikes in the modeled sensible heat flux occurred when the modeled planetary boundary layer (PBL) was convectively unstable, while the observed PBL remained stably stratified. Surface temperature errors were not always associated with errors in turbulent heat flux. For example, the modeled sensible heat flux agrees well with observations during the last 2 weeks of December, when the surface temperature errors are still large. The downward heat flux spikes in the model are associated with high $10 \mathrm{~m}$ winds (that were correctly predicted by the model) and varying degrees of stratification. During these pe- riods the observed stratifications were not systematically different from those in the model. Hence the origin of these erroneous downward spikes is not clear and requires more detailed study. They seem to occur mainly during periods of snowfall, but a causal link has not been found. A more informative analysis of the surface fluxes may be possible when the simulation has been repeated using an improved ice model. It is noteworthy that large downward sensible heat flux spikes were also predicted on these dates in the single-column modeling study of Pinto et al. [1999], even though the surface temperatures in their model agreed well with observations.

The upward latent heat flux in the ECMWF model averaged $1.3 \mathrm{~W} \mathrm{~m}^{-2}$ and was $<5 \mathrm{~W} \mathrm{~m}^{-2}$ in magnitude for $91 \%$ of the period (not shown). The small contribution of the latent heat flux to the surface energy budget in the model is not surprising since latent heat flux is significantly less than sensible heat flux at surface temperatures around $-20^{\circ} \mathrm{C}$ [e.g., Andreas and Cash, 1996]. Observational estimates of latent heat fluxes were not available at the time of this study.

Modeled downward longwave irradiance at the surface of the model was in remarkably good agreement with observations, as shown in Figure 5. The average predicted downward flux of $177 \mathrm{~W} \mathrm{~m}^{-2}$ for November and December is well within the uncertainty range of the observations. Periods of disagreements between the model and observations are partially explained by low cloud errors in the ECMWF model, as described below. The errors in upward longwave irradiance (not shown) are qualitatively similar to corresponding errors in surface temperature shown in Figure 1. No shortwave radiation was reaching the surface at SHEBA site during November and December, except for the first several days, when the noontime maximum was $\sim 5 \mathrm{~W} \mathrm{~m}^{-2}$.

\section{Clouds and Precipitation}

The National Oceanic and Atmospheric Administration Environmental Technology Laboratory operated an $8 \mathrm{~mm}$ wavelength (Ka-band) vertically pointing cloud and precipitation radar (described by Moran et al. [1998]) and a scanning lidar (described by Grund and Sandberg [1996]) for the entire SHEBA annual cycle. The radar recorded reflectivities and Doppler velocities at $45 \mathrm{~m}$ vertical resolution every $9 \mathrm{~s}$, and the 

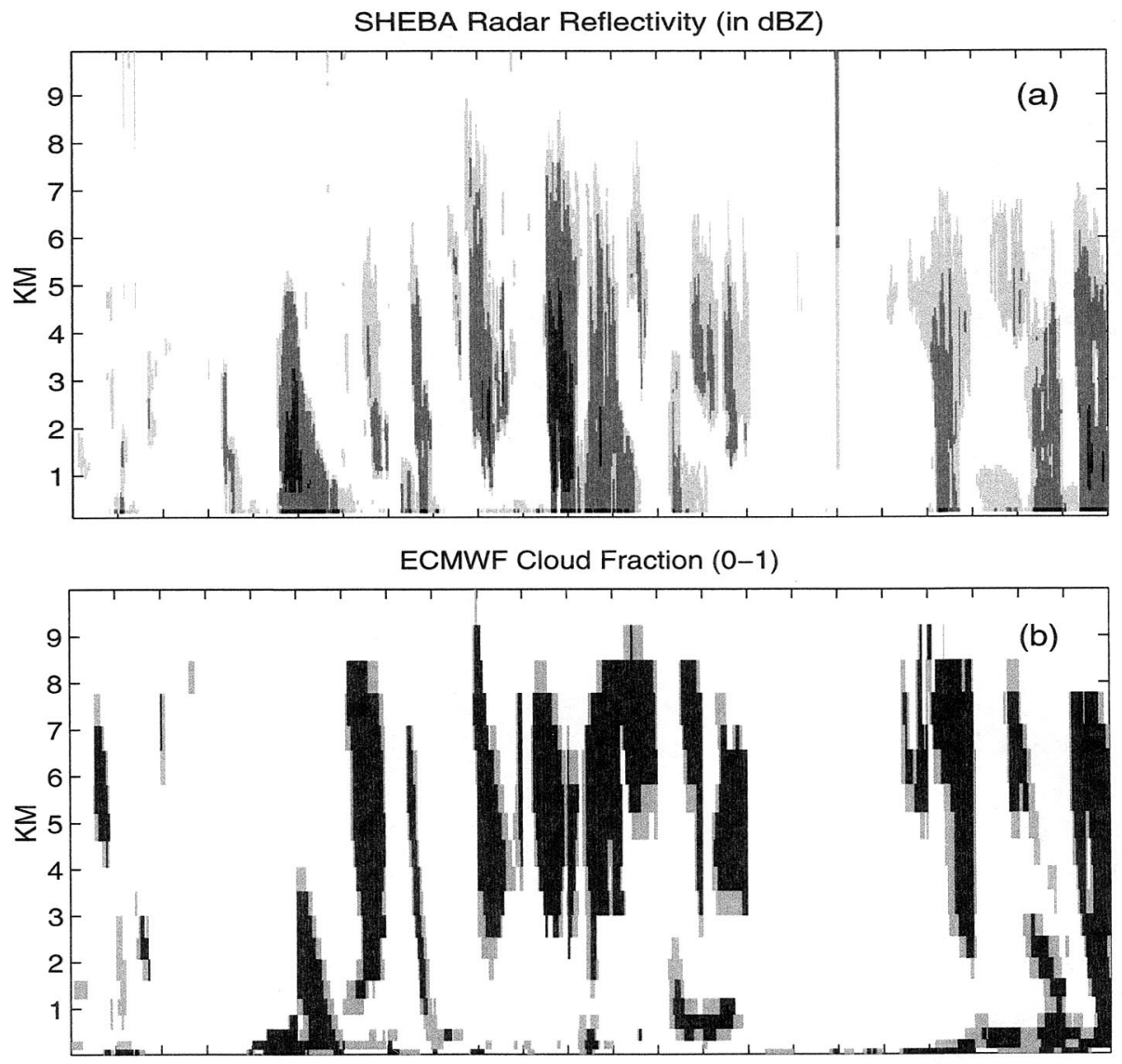

Estimated Precipitation Content (in $\mathrm{g} / \mathrm{m}^{3}$ )

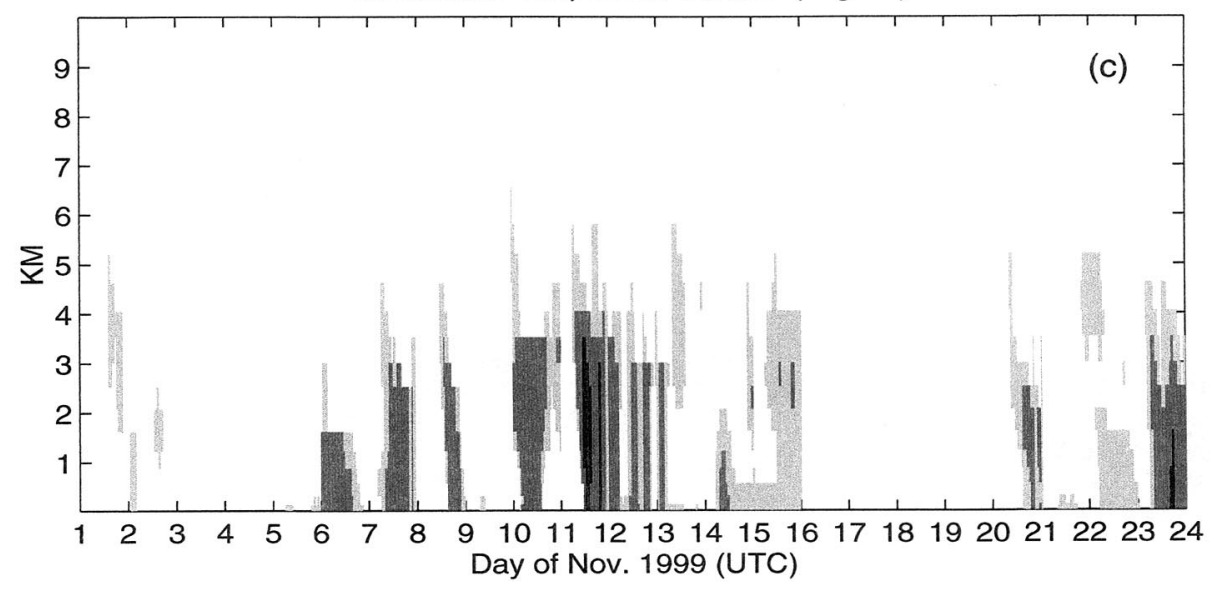

Figure 6. (a) Profiles of hourly-averaged radar reflectivity measured at the SHEBA camp. Reflectivities below $-30 \mathrm{dBZ}$ are unshaded, are light gray from -30 to $-15 \mathrm{dBZ}$, and are dark gray from -15 to $0 \mathrm{dBZ}$, and those $>0 \mathrm{dBZ}$ are black. (b) Cloud fraction and (c) precipitation content in the ECMWF model. In Figure $6 \mathrm{~b}$ a cloud fraction $<0.2$ is white, $0.2-0.8$ is gray, and $>0.8$ is black. The precipitation content shown in Figure $6 \mathrm{c}$ is derived from the modeled precipitation rate assuming an average fall speed of $1 \mathrm{~m} \mathrm{~s}^{-1}$. A precipitation content $<0.001 \mathrm{~g} \mathrm{~m}^{-3}$ is unshaded, $0.001-0.01 \mathrm{~g} \mathrm{~m}^{-3}$ is light gray, $0.01-0.1 \mathrm{~g} \mathrm{~m}^{-3}$ is dark gray, and $>0.1 \mathrm{~g}$ $\mathrm{m}^{-3}$ is black.

lidar recorded backscatter and depolarization ratios at $30 \mathrm{~m}$ vertical resolution every $5 \mathrm{~s}$. With additional processing the combined measurements from these two sensors are capable of providing detailed information on cloud presence, phase, vertical extent, and layering, as well as information about particle size and concentrations in single-phase (ice or liquid) clouds or precipitation. In this study, we use hourly-averaged vertical profiles of radar reflectivity (available for November 1-24, 1997) and lidar depolarization ratio to evaluate the presence and phase of clouds and precipitation in the ECMWF model. 
The ECMWF model includes prognostic cloud fraction, cloud condensate content, and precipitation fluxes [see Tiedke, 1993; Jakob and Klein, 1999]. Cloud fraction is affected by large-scale advection, cloud formation processes, and evaporation. The cloud condensate content is affected by large-scale advection, turbulent and convective transports, condensation, evaporation, conversion to precipitation, and entrainment. Condensate phase is a diagnostic function of temperature, ramping parabolically from $100 \%$ ice at $250 \mathrm{~K}$ to $100 \%$ liquid at $273 \mathrm{~K}$. Cloud ice particles, which are assumed to be falling, are converted to snow as they leave the model level. Rain is formed by the conversion of cloud liquid. In the model both rain and snow can evaporate in subsaturated conditions, and snow is assumed to melt at temperatures above freezing. Cloud radiative properties are computed as a function of cloud fraction, condensate content, and condensate phase. Precipitation has no direct effect on radiative transfer.

Three comparisons were performed. First, hourly model cloud fraction profiles were compared with cloud fraction deduced from hourly averages of the radar observations. Second, a synthetic radar reflectivity was computed from the model's microphysical variables and was compared with hourly averages of the observed reflectivity. Last, the model-predicted cloud phase was compared with the lidar depolarization.

\subsection{Cloud Occurrence}

A strong correlation was found between the time-dependent profiles of observed radar reflectivity and ECMWF model cloud amount during the first 24 days of November, as shown in Figures $6 \mathrm{a}$ and $6 \mathrm{~b}$. Both the model and radar indicated that the majority of the troposphere was clear on days 2-5 and 16-19 and relatively cloudy for the rest of the period. There was also considerable agreement between model and radar reflectivity on a daily timescale. However, the frequency of cloud below $1 \mathrm{~km}$ in the model was significantly greater than that implied by the cloud radar. Another difference is that upper level clouds in the model did not extend as low as corresponding regions of radar reflectivity. Since precipitation particles are larger than cloud particles and radar reflectivity of a given mass of particles is proportional to the third power of effective radius, a relatively small amount of precipitation is needed to produce a radar reflectivity comparable to cloud condensate. We estimated the precipitation content (in $\mathrm{g} \mathrm{m}^{-3}$ ) from the model's precipitation rate profiles and an assumed fall speed of $1 \mathrm{~m} \mathrm{~s}^{-1}$, which is typical of snowflakes [Locatelli and Hobbs, 1974]. The estimated precipitation content was often $>0.01 \mathrm{~g} \mathrm{~m}^{-3}$ and sometimes was of comparable magnitude to cloud condensate content. When the reflectivity was high (e.g., on November 12, the model results suggest that its vertical extent was considerably augmented by subcloud precipitation.

Cloud or precipitation was judged to be present when and where the radar reflectivity at SHEBA exceeded a threshold level (empirically defined as a linear function of height passing through $-25 \mathrm{~dB}$ at $0.5 \mathrm{~km}$ and $-15 \mathrm{~dB}$ at $10 \mathrm{~km}$ on the basis of high-resolution radar reflectivity plots). Figure 7 shows average vertical profiles of the mean cloud fraction in the model, the additional contribution if precipitation is treated as $100 \%$ cloud cover when and where it occurs, and the frequency of above-threshold radar reflectivity for the first 24 days of November. The model results emphasize the frequent role of subcloud precipitation in creating radar reflectivity, especially below $4 \mathrm{~km}$. The model agreed well with observations at ele-

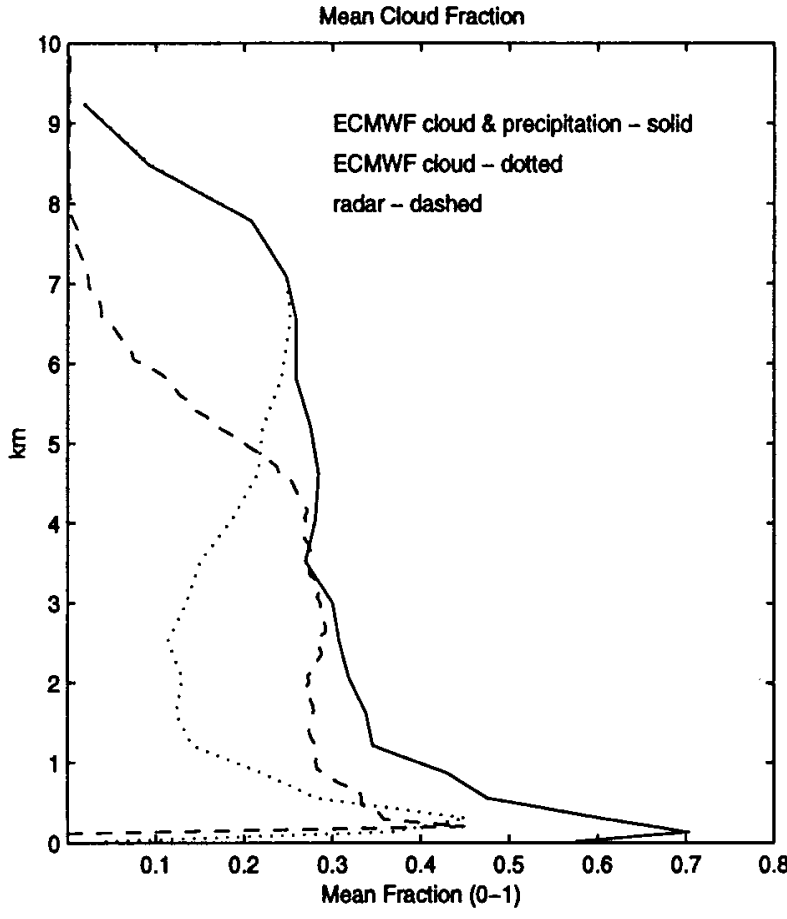

Figure 7. Mean profiles of cloudiness and precipitation presence in the ECMWF model and as deduced from radar reflectivity during November 1-24, 1997. The dotted line is the mean profile of cloud fraction in the model. The solid line also includes the contribution of precipitation, where a precipitation content $>0.001 \mathrm{~g} \mathrm{~m}^{-3}$ (i.e., the shaded area of Figure $6 \mathrm{c}$ ) is assigned a cloud fraction of 1 . The dashed line is the mean profile of cloud or precipitation presence estimated from radar reflectivity at SHEBA. Cloud fraction is 1 when and where the hourly-averaged radar reflectivity exceeds the threshold level defined in the text, which includes almost all of the nonblack area in Figure 6a.

vations between 2 and $5 \mathrm{~km}$ but overpredicted cloud or precipitation frequency below and above this layer. The decrease in radar sensitivity with height may have caused cloud top heights or upper level cloud occurrence at SHEBA to be underestimated. For example, the lidar instrument detected more cloudiness above $5 \mathrm{~km}$ than radar detected on November 7, 15, and 19 . Hence comparing model results with radar reflectivity alone may have exaggerated the model errors at higher levels.

3.1.1. Skill of ECMWF cloud scheme. Three categories of cloud cover were compared: lower $(<2 \mathrm{~km})$, upper $(>2 \mathrm{~km})$, and total cloud cover. In the ECMWF model the "lower" region corresponds to the lowest eight model layers (of 31 total). A category of cloud was assumed present in the observations if radar reflectivity exceeded the threshold anywhere in the vertical range of that category. This scheme occasionally classified precipitation as low cloud but not often enough to seriously bias our results. For the model we defined upper and lower level cloudiness as the maximum cloud fraction among the model levels within each height category. In other words, the clouds within each height category were assumed to be maximally overlapping (vertically stacked on top of each other). Total cloud cover, however, was computed assuming that upper and lower level cloud amounts are randomly overlapped (upper level cloud is spatially uncorrelated with lower level 
Table 1. Matrix Showing the Percentage of Time the Radar Data and the ECMWF Model Agree and Disagree for Total Cloud Cover for November 1-24, 1997

\begin{tabular}{lcc}
\hline & \multicolumn{2}{c}{ Radar } \\
\cline { 2 - 3 } & Cloud Present & Cloud Not Present \\
\hline ECMWF & & \\
Cloud Present & $59 \%$ & $28 \%$ \\
Cloud Not Present & $3 \%$ & $10 \%$ \\
\hline
\end{tabular}

cloud within a grid column) since they typically are formed independently. A category of cloud was assumed present during a given hour in the model if cloudiness exceeded $50 \%$. Tables 1-3 show the frequency of cloud occurrence in the model and observations for the three categories. The average lower level cloud fraction in the model (74\%) was $21 \%$ greater than observations, but no comparable bias was seen at upper levels. The ECMWF model correctly predicted the occurrence of cloudy and clear conditions $69 \%$ of the time for total cloud cover, $55 \%$ at lower levels, and $73 \%$ at upper levels. Over a 24 day period, a random number generator with the correct mean cloudiness at upper and lower levels would make correct hourly predictions $55 \%$ of the time for total cloud, $50 \%$ for lower level cloud, and $50 \%$ for upper level cloud. The random cloud predictor skill has a standard deviation of $2.3 \%$ for each cloud category; hence the ECMWF model did have significant skill in cloud forecasting during this period, especially for upper level cloud.

3.1.2. Associations between lower level cloud and surface quantities. The relationship between the occurrence of lower level cloud and observed surface quantities was assessed using the cloud radar and measurements of $2 \mathrm{~m}$ air temperature, sensible heat flux, and downward longwave irradiance. The results shown in Table 4 indicate that as one would expect, the presence of lower level cloud was associated with higher-thanaverage downward longwave irradiance, surface temperature, and upward sensible heat flux.

Table 5 lists the errors in the ECMWF model for these surface quantities and how they were associated with predicted cloudiness. On the basis of the information in Table 4, one would expect model errors in surface air temperature, upward sensible heat flux, and downward longwave irradiance to be more positive if lower level cloud was incorrectly included in the model forecast and more negative when lower level cloud was incorrectly omitted. The model errors shown in Table 5 are consistent with these predictions for downward irradiance and, to a lesser extent, for sensible heat flux. Surface air temperature errors were large and positive when no low level clouds were observed $($ radar $=\mathrm{N}$ in Table 5), independent of the accuracy of low level cloud forecast. This may be explained by

Table 2. As in Table 1 but for Lower Level Cloud Cover for November 1-24, 1997

\begin{tabular}{lcc}
\hline & \multicolumn{2}{c}{ Radar } \\
\cline { 2 - 3 } & Cloud Present & Cloud Not Present \\
\hline ECMWF & & \\
Cloud Present & $41 \%$ & $33 \%$ \\
Cloud Not Present & $12 \%$ & $14 \%$ \\
\hline
\end{tabular}

Table 3. As in Table 1 but for Upper Level Cloud Cover for November 1-24, 1997

\begin{tabular}{lcc}
\hline & \multicolumn{2}{c}{ Radar } \\
\cline { 2 - 3 } & Cloud Present & Cloud Not Present \\
\hline ECMWF & $29 \%$ & $13 \%$ \\
Cloud Present & $14 \%$ & $44 \%$ \\
Cloud Not Present & & \\
\hline
\end{tabular}

the observed association between cloud-free conditions and negative temperature perturbations (e.g., days 4 and 15-20), which the model was unable to capture owing to its artificially large surface heat capacity.

The downward longwave irradiance predicted by the ECMWF model was very close to observations when low clouds were absent in both the model and radar measurements. When lower level clouds were correctly predicted, the ECMWF model underestimated the surface downward longwave radiation by $10 \mathrm{~W} \mathrm{~m}^{-2}$ on average. This is consistent with Walsh and Chapman's [1998] comparison of the ECMWF reanalysis with Russian ice station data archives, which found that the model underestimated the impact of clouds on the surface radiative budget throughout the year. The negative bias in downward radiation in the presence of lower level cloud may be because the model did not include the emissivity of precipitation. Another possible explanation is that the model underestimated the emissivity of the low level clouds, which would occur if the modeled cloud condensate content were too low or if the modeled condensate phase were predominantly ice when the actual cloud phase was liquid [e.g., see Rockel et al., 1991]. It is shown in section 3.3 that the ECMWF model tended to underestimate the frequency that clouds were predominantly liquid during this period. The average model bias in downward longwave irradiance was small during this period owing to compensating errors: The model tended to overpredict the occurrence of lower level clouds but underestimated downward longwave irradiance when they were present.

\subsection{Radar Reflectivity by Clouds and Precipitation}

The cloud radar measurements from SHEBA cannot be compared directly with cloud and precipitation variables from the ECMWF model. Our present data are for reflectivity alone, so for comparison we have estimated the reflectivity of model clouds and precipitation. The ECMWF model cloud and precipitation microphysics are not based on a consistent assumption about the underlying size distribution of cloud condensate and hydrometeors. Since radar reflectivity depends strongly on the sizes of the reflecting particles, our reflectivity estimates of the model's clouds and precipitation are somewhat uncertain.

Table 4. Average of Surface Variables Observed at SHEBA Ice Camp, November 1-24, 1997

\begin{tabular}{lccc}
\hline Low Cloud Presence & $T(2 \mathrm{~m}), \mathrm{K}$ & $\begin{array}{c}\text { Upward SH, } \\
\mathrm{W} \mathrm{m}^{-2}\end{array}$ & $\begin{array}{c}\text { Downward LW, } \\
\mathrm{W} \mathrm{m}^{-2}\end{array}$ \\
\hline All data & 253.4 & -1.0 & 213.4 \\
With low cloud & 257.1 & +1.3 & 241.3 \\
No low cloud & 249.2 & -3.7 & 181.7 \\
\hline
\end{tabular}




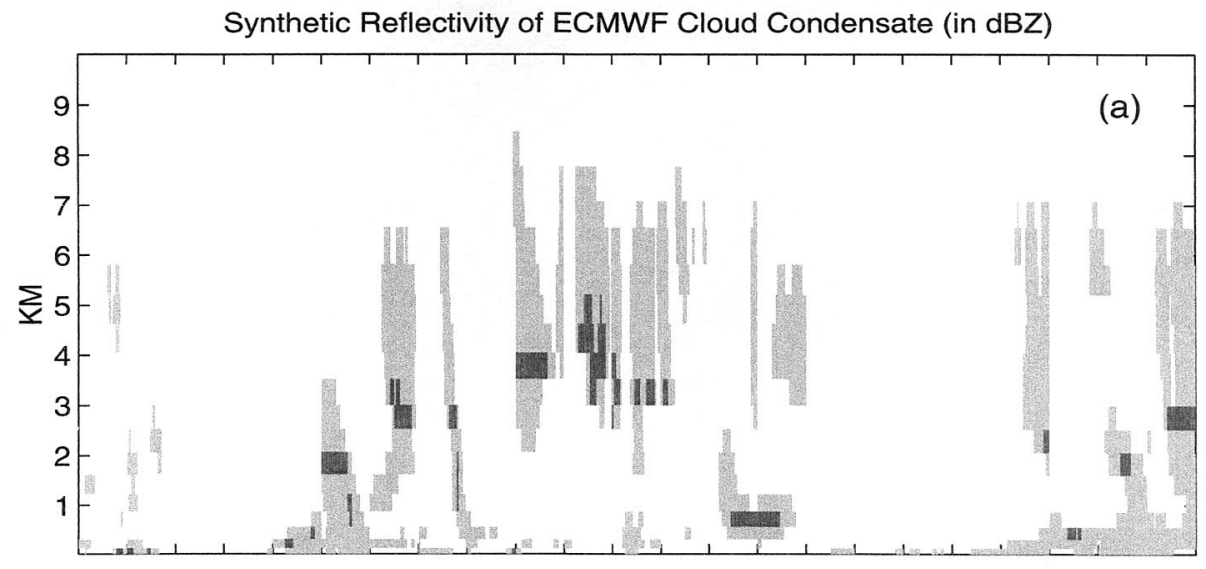

Synthetic Reflectivity of ECMWF Cloud and Snow (in dBZ)

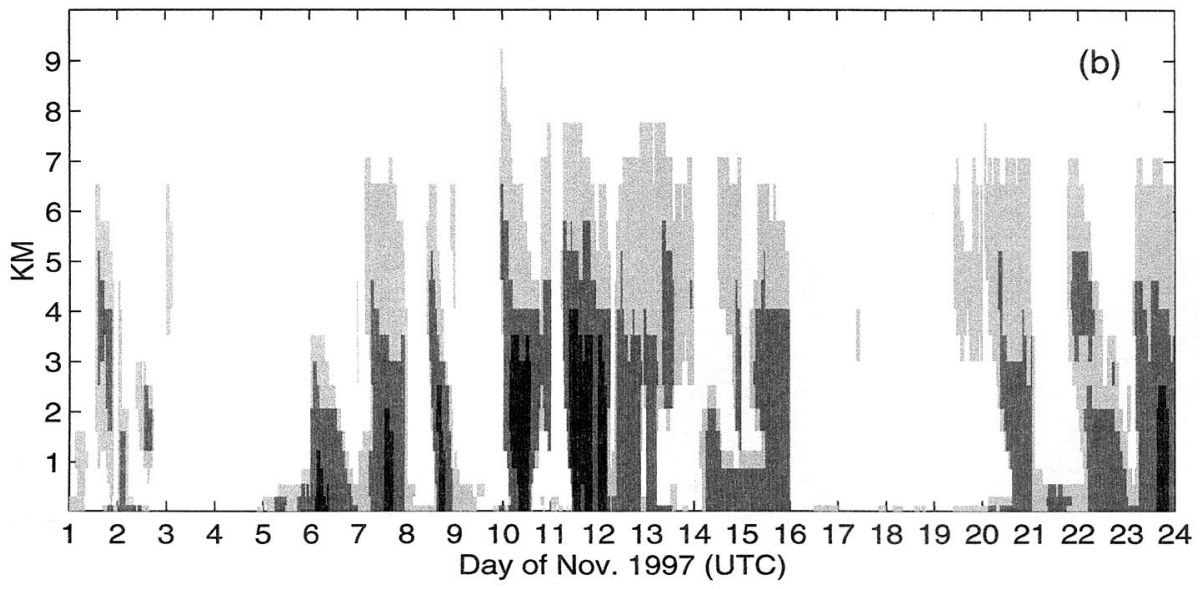

Figure 8. Synthetic reflectivity estimated from ECMWF model variables, with the same shading scheme as in Figure 6 (less than $-30 \mathrm{dBZ}$ is unshaded, -30 to $-15 \mathrm{dBZ}$ is light gray, -15 to $0 \mathrm{dBZ}$ is dark gray, and $>0 \mathrm{dBZ}$ is black). (a) The reflectivity of cloud condensate only, as estimated using (1). The reflectivity in Figure 8 a does not exceed $0 \mathrm{dBZ}$. (b) The combined reflectivity of modeled cloud condensate and snowfall, as estimated using (2).

We estimated the reflectivity of model cloud condensate alone using the following equation:

$$
Z_{e}=a W r_{e}^{3},
$$

where $a$ is a coefficient $\left(49.6 \times 10^{-6}\right.$ for liquid, $9.4 \times 10^{-6}$ for ice) from Matrosov [1999], $W$ is liquid or ice water content (in $\mathrm{g} \mathrm{m}^{-3}$ ) (which is predicted by the ECMWF model), and $r_{e}$ is an assumed effective radius of the cloud particles in the ECMWF model radiation scheme (10 $\mu \mathrm{m}$ for liquid and $40 \mu \mathrm{m}$ for ice).

Table 5. Average Error of Surface Variables in the ECMWF, November 1-24, 1997

\begin{tabular}{lccc}
\hline \multicolumn{1}{c}{ Low Cloud Presence } & $T(2 \mathrm{~m}), \mathrm{K}$ & $\begin{array}{c}\text { Upward SH, Downward LW, } \\
\mathrm{W} \mathrm{m}^{-2}\end{array}$ & $\mathrm{~W} \mathrm{~m}^{-2}$ \\
\hline Average & +3.0 & -5.5 & -1.1 \\
$\mathrm{ECMWF}=\mathrm{Y}$, radar $=\mathrm{Y}$ & -0.5 & -10.2 & -10.3 \\
$\mathrm{ECMWF}=\mathrm{Y}$, radar $=\mathrm{N}$ & +6.2 & +2.4 & +20.9 \\
$\mathrm{ECMWF}=\mathrm{N}$, radar $=\mathrm{Y}$ & -0.6 & -18.6 & -31.2 \\
$\mathrm{ECMWF}=\mathrm{N}$, radar $=\mathrm{N}$ & +8.8 & +2.4 & +0.3 \\
\hline
\end{tabular}

Error is defined as modeled minus observed value.
Figure 8a shows a time-height plot of the implied reflectivity of model clouds. Comparison with Figure 6a shows that this reflectivity is commonly smaller than observations by an order of magnitude (10 dBZ), suggesting that precipitation is often the dominant source of reflectivity.

To estimate the reflectivity of model-predicted precipitation, we assume that it fell as snow (as was observed). Matrosov [1992] derived a relationship between snowfall rate $R$ and radar reflectivity $Z_{e}$ of the form

$$
Z_{e}=A R^{b} .
$$

The parameters $A$ and $b$ (28.0 and 0.95, respectively) were computed by Matrosov [1992] by assuming a snowflake size distribution, $N(D)=N_{0} \exp (-\Lambda D)$, suggested by Sekhon and Srivastava [1970] on the basis of observations of midlatitude snowfalls. Here $D$ is the diameter of a melted snowflake, $N$ is a number concentration per diameter, and the parameters $N_{0}$ and $\Lambda$ are empirical functions of $R$ (also of the form $E R^{f}$, where $E$ and $f$ are constants). As a consistency check, (2) was used to predict the accumulated snowfall for days 1-24 of November from the time series of reflectivity and was found to be a considerable underestimate compared to the snow line 

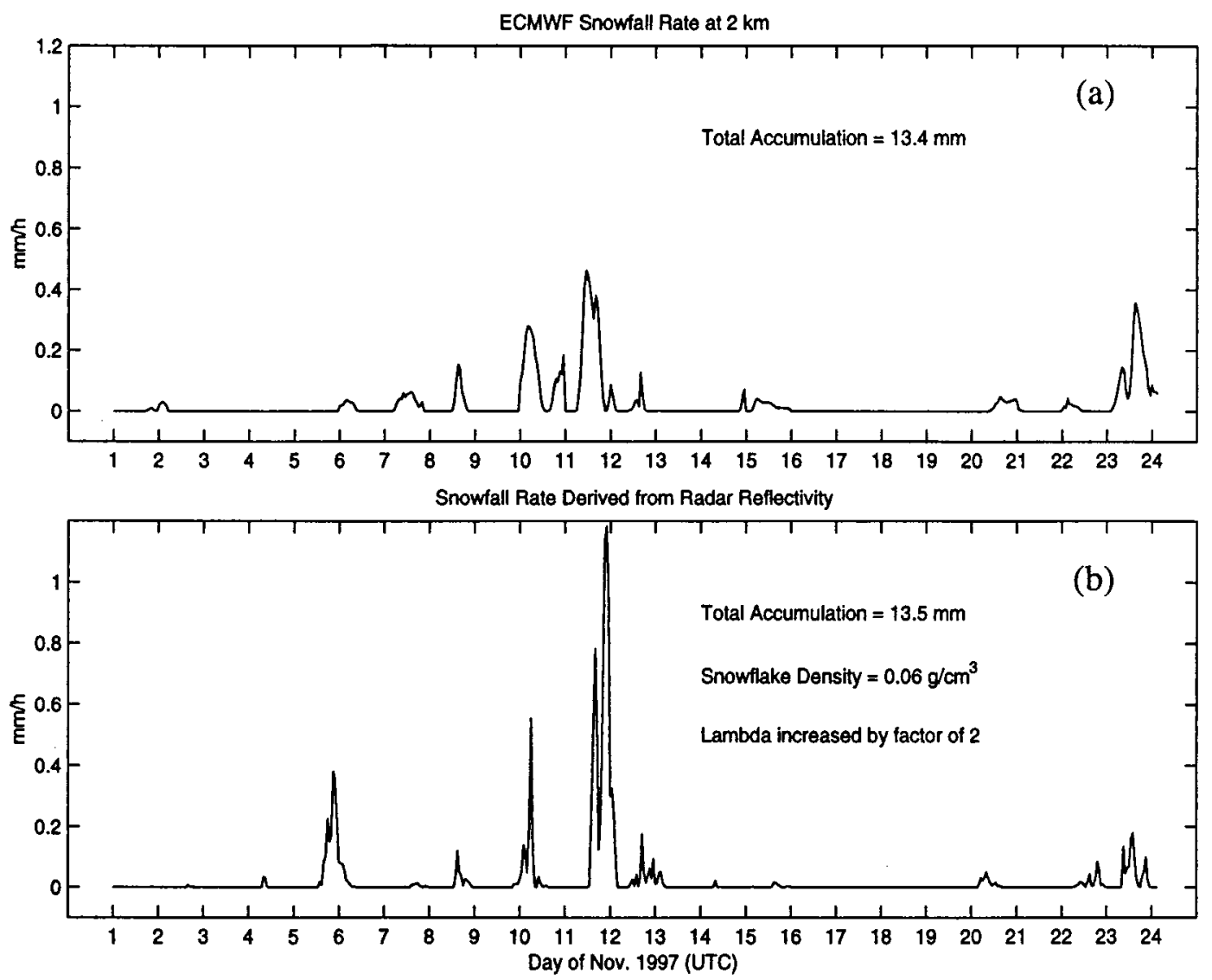

Figure 9. Modeled and radar-estimated snowfall rate at $2 \mathrm{~km}$ elevation at the SHEBA ice camp for November 1-24, 1997. In Figure $9 \mathrm{~b}$ the rate is estimated from radar reflectivity using (2) and increasing the parameter $\Lambda$ by a factor of 2 .

observations discussed in section 2.1. A much better estimate was obtained by doubling $\Lambda$, which greatly reduces the relative abundance of large snowflakes (see Figure 9). Using this modified $\Lambda$ has the effect in (2) of reducing $A$ from 28 to 6.5 .

We used (2) to compute the precipitation reflectivity from the model-predicted precipitation rate at each level and hour. Figure $8 \mathrm{~b}$ shows a time-height section of the combined radar reflectivity of the model-predicted cloud and snowfall. This is in much better agreement with the observations (shown in Figure 6a) than the cloud reflectivity alone. The observed radar reflectivity peaks tend to be more intense and shorter in duration, which one might expect since the model grid column represents a $(60 \mathrm{~km})^{2}$ areal average, while the observations are at a point.

\subsection{Cloud Phase}

SHEBA upward pointing lidar measurements for November and December of 1997 were processed to determine backscattered lidar depolarization ratio $\delta$. This is a measure of cloud phase since $\delta$ is typically $<0.1$ for liquid condensate and $>0.3$ for ice particles [Sassen, 1991]. Values of $\delta$ between 0.1 and 0.3 are ambiguous; they may indicate mixed phase cloud but can result from pure ice cloud as well (the depolarization ratio backscattered from ice crystals can vary over a wide range depending on crystal size and geometry [e.g., Sassen, 1991]). Figure 10a shows the frequency distribution of observed $\delta$ over all clouds in our data. A sharp peak is seen at 0-0.1 (liquid clouds) and a broad peak is seen from 0.2 to 0.4 . A 3 day time series of measured $\delta$ is shown in Figure 11. Each 5 min sample is used to deduce a cloud base which we associate with the contemporaneous $\delta$, and $\delta$ is indicated by an appropriate symbol at the cloud base height. A general increase is seen in $\delta$ for greater cloud base heights, consistent with upper clouds predominantly composed of ice and lower clouds that are more often liquid, but low $\delta$ clouds were seen up to $5 \mathrm{~km}$ above the surface. Figure 10b shows how depolarization is associated with cloud base temperature (deduced from cloud base height and the model temperature profile, which is very close to sonde values). The expected trend toward a larger fraction of ice cloud at colder temperatures is evident, as previously shown by Intrieri et al. [1999]. However, either phase of condensate can occur over a wide range of temperatures, with liquid clouds existing at temperatures as low as $239 \mathrm{~K}$ and ice particles (probably snow) remaining quite common near freezing. Furthermore, at most temperatures, at least half the measured $\delta$ are ambiguous. For comparison, Figure 10b also shows the partitioning of cloud condensate phase in the ECMWF model between ice and liquid. The lidar observations suggest liquid clouds were more common at temperature between 240 and $260 \mathrm{~K}$ than the model predicted. The weak relationship between $\delta$ and temperature suggests that factors other than temperature are strongly influencing cloud phase and that improvements in model performance will require more than simply adjusting the temperature dependence of the cloud phase parameterization. The observational analysis of Pinto 
(a)
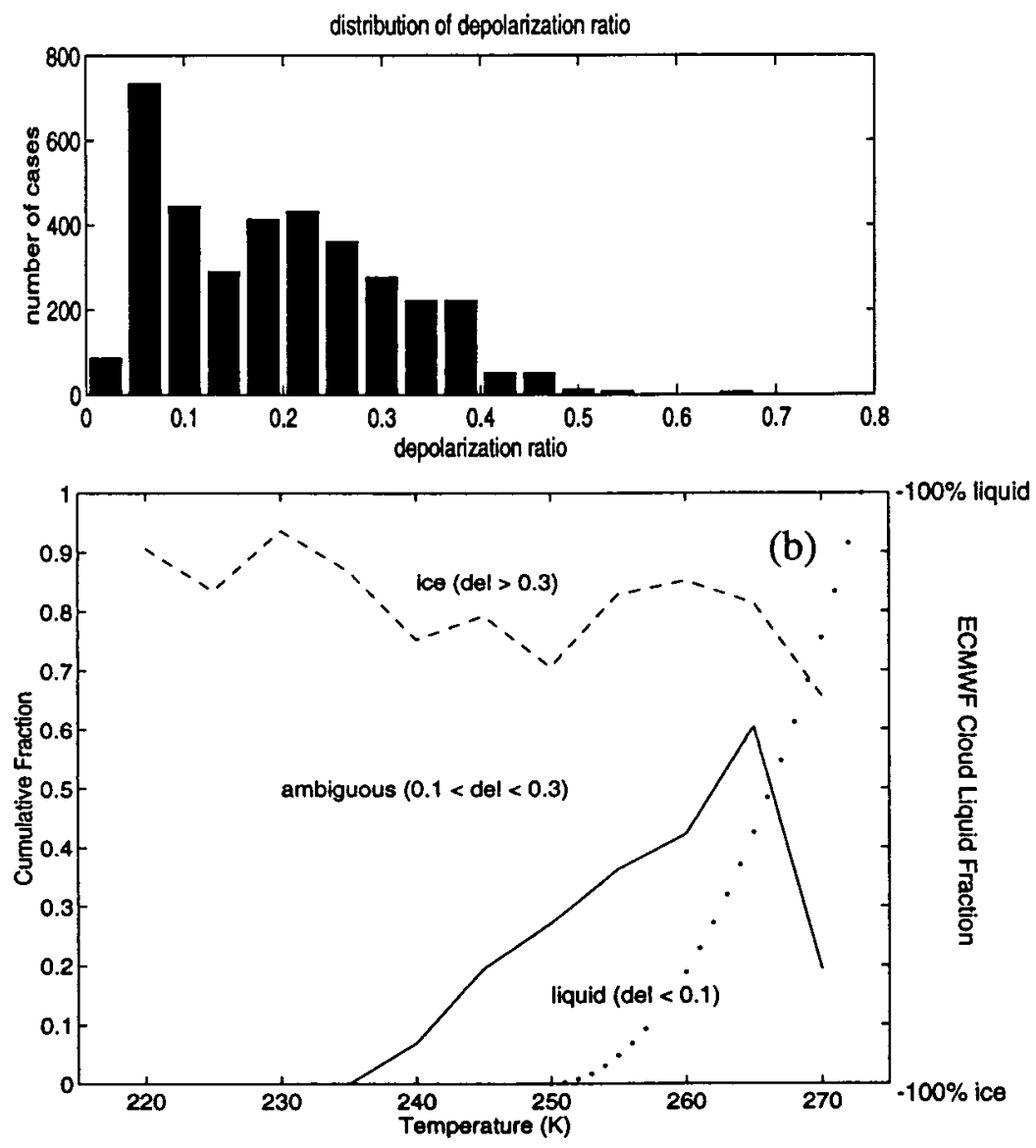

Figure 10. Depolarization ratio statistics for lidar measurements during November and December 1997. (a) The depolarization ratio frequency distribution and (b) the relationship between cloud base temperature and condensate phase as inferred from the depolarization ratio ("del"). Reading vertically from a given temperature on the horizontal axis, the distance to the solid line is the fraction of clouds that are liquid, the distance between the solid line and the dashed line is the fraction of clouds whose phase is ambiguous, and the remainder are ice clouds. The dotted line in Figure 10b represents how cloud condensate is partitioned between liquid and ice as a function of temperature in the ECMWF model (scale on right).

[1998] and modeling study of Harrington et al. [1999] both cited the abundance of ice particle formation nuclei (IFN) as an important factor in determining the amounts of ice and liquid in Arctic clouds at this temperature range. However, the factors controlling IFN concentration are not well known.

\section{Conclusions}

The SHEBA measurements have provided a detailed look at Arctic cloud and boundary layer development during the Arctic winter and thus provided an opportunity to test aspects of the physical parameterizations in the ECMWF operational model under unique conditions. The assimilation of temperature, humidity, wind, and height at standard pressure levels kept the overall thermodynamic state fairly close to observations, which meant that the physical parameterizations were the main cause of errors in the variables of interest. In many respects, the model performed quite well. The predicted clouds, precipitation, and downward longwave radiation agreed well with SHEBA observations from November and December of 1997. The most prominent discrepancies between the ECMWF model and observations were the following: (1)
The modeled surface temperature was much less variable than observations owing to the parameterization of sea ice as an isothermal slab. (2) Sporadic large errors occurred in the surface turbulent heat flux. Positive (upward) heat flux errors occurred when surface temperature errors produce convectively unstable conditions. The cause of the negative heat flux errors is not yet clear. (3) The model predicted too much cloudiness at elevations below $1 \mathrm{~km}$. (4) Downward longwave irradiance was underestimated when low clouds were present.

The observed radar reflectivity and precipitation were not consistent with a $Z-R$ relationship based on a standard midlatitude snowflake size distribution from Sekhon and Srivastava [1970]. Hence we modified the $Z-R$ relationship to substantially reduce the proportion of large flakes. We used this relation and a prediction of the reflectivity from model clouds to compute a synthetic reflectivity for the ECMWF model and found this was in fair agreement with the observations. The reflectivity was dominated by precipitation rather than clouds most of the time.

Lidar depolarization measurements at SHEBA indicate that both liquid and ice phase clouds occurred over a wide range of 


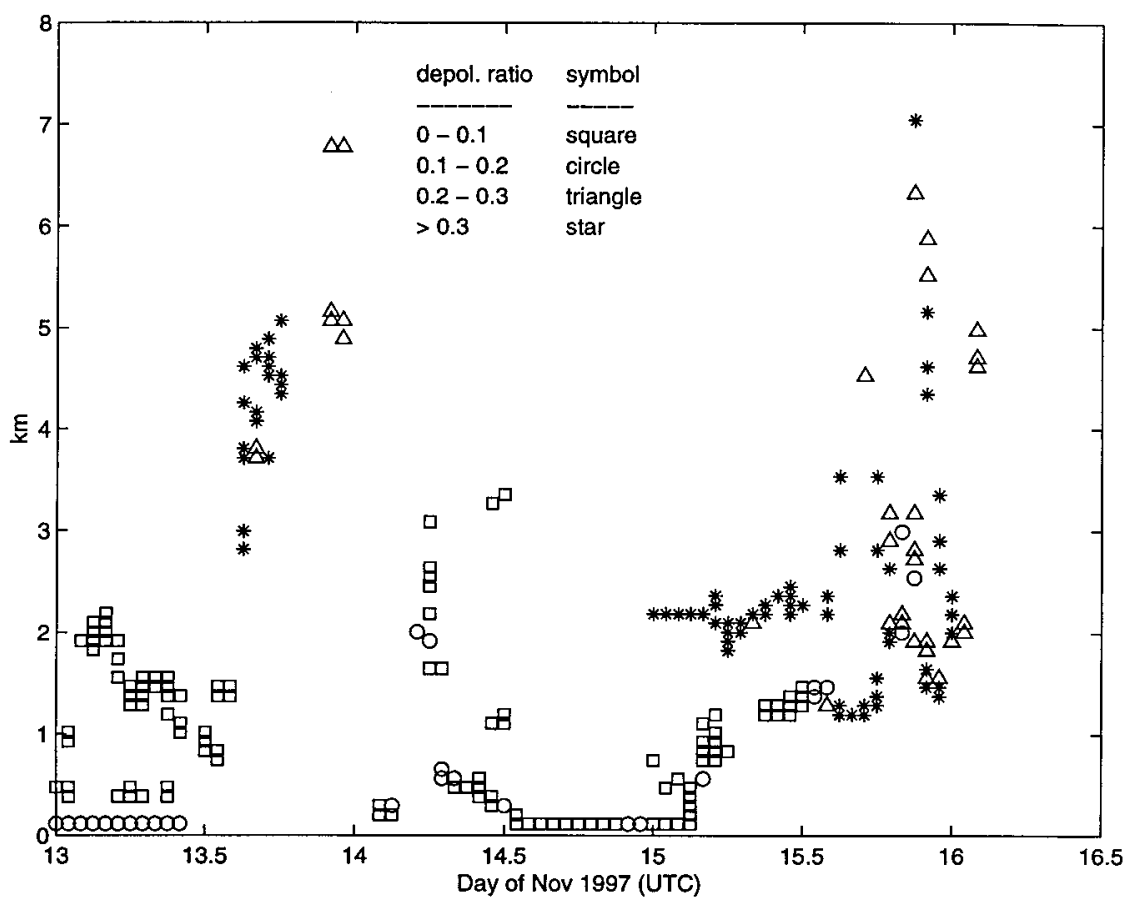

Figure 11. Depolarization ratio of backscattered lidar as a function of time and cloud base height for November 13-16, 1997. Values from 0 to 0.1 are indicated by a square, from 0.1 to 0.2 are indicated by a circle, from 0.2 to 0.3 are indicated by a triangle, and $>0.3$ are indicated by a star. A ratio $<0.1$ indicates liquid condensate, and values $>0.3$ indicate ice, and intermediate values are ambiguous.

temperatures as low as $239 \mathrm{~K}$ during this period. The simple, temperature-dependent cloud phase parameterization in the ECMWF model appears to have underestimated the frequency of liquid water clouds. The overall correlation of cloud-based temperature with lidar depolarization ratio was not strong, suggesting that factors other than temperature are important in determining cloud phase in this temperature range.

The results of this study have already inspired some work toward improving the physics of the ECMWF model, including a revision of the sea ice thermodynamics. In the future, we hope to perform a similar comparison using data from other phases of the annual cycle at SHEBA.

Acknowledgments. We thank Dick Moritz for providing snow gauge data and surface meteorological reports from SHEBA, Sergey Matrosov for advice on estimating radar reflectivity from precipitation rates and cloud variables, and Don Perovich for providing snow depth data obtained at SHEBA. We thank colleagues in the SHEBA Atmospheric Surface Flux Group, Chris Fairall, Peter Guest, and Ola Persson, for help collecting and processing the data. Paul Neiman, Ola Persson, and two anonymous reviewers provided valuable comments that improved the manuscript. This research was supported by NASA grant NAG1-1711 and several grants from the National Science Foundation Office of Polar Programs.

\section{References}

Andreas, E. L, and B. A. Cash, A new formulation for the Bowen ratio over saturated surfaces, J. Appl. Meteorol., 35, 1279-1289, 1996.

Andreas, E. L, C. W. Fairall, P. S. Guest, and P. O. G. Persson, An overview of the SHEBA atmospheric surface flux program, paper presented at 5th Conference on Polar Meteorology and Oceanography, Am. Meteorol. Soc., Dallas, Tex., Jan. 10-15, 1999.

Grund, C. J., and S. P. Sandberg, Depolarization and backscatter lidar for unattended operation, in Advances in Atmospheric Remote Sensing With Lidar: Selected Papers of the 18th International Laser Radar
Conference, edited by A. Ansmann et al., pp. 3-6, Springer-Verlag, New York, 1996.

Harrington, J. Y., T. Reisin, W. R. Cotton, and S. M. Kreidenweis, Cloud-resolving simulations of arctic stratus, part II, Transitionseason clouds, Atmos. Res., 51, 45-75, 1999.

Intrieri, J. M., C. W. Fairall, and B. J. McCarty, Lidar-derived Arctic cloud properties and radiation measurements during the polar winter season at SHEBA, paper presented at 5th Conference on Polar Meteorology and Oceanography, Am. Meteorol. Soc., Dallas, Tex., Jan. 10-15, 1999.

Jakob, C., and S. A. Klein, The role of vertically varying cloud fraction in the parameterization of microphysical processes in the ECMWF model, Q. J. R. Meteorol. Soc., 125, 941-965, 1999.

Locatelli, J. D., and P. V. Hobbs, Fallspeeds and masses of solid precipitation particles, J. Geophys. Res., 79, 2185-2197, 1974.

Matrosov, S. Y., Radar reflectivity in snowfall, IEEE Trans. Geosci. Remote Sens., 30, 454-461, 1992.

Matrosov, S. Y., Retrievals of vertical profiles of ice cloud microphysics from radar and infrared measurements using tuned regressions between reflectivity and cloud parameters, J. Geophys. Res., 104, 16,741-16,753, 1999.

Maykut, G. A., Energy exchange over young sea ice in the central Arctic, J. Geophys. Res., 83, 3646-3658, 1978.

Moran, K. P., B. E. Martner, M. J. Post, R. A. Kroplfi, D. C. Walsh, and D. B. Widener, An unattended cloud profiling radar for use in climate research, Bull. Am. Meteorol. Soc., 79, 443-455, 1998.

Perovich, D. K., et al., Year on ice gives climate insights, Eos Trans. $A G U, 80,483-486,1999$.

Pinto, J. O., Autumnal mixed-phase cloudy boundary layers in the Arctic, J. Atmos. Sci., 55, 2016-2038, 1998.

Pinto, J. O., J. A. Curry, A. H. Lynch, and P. O. G. Persson, Modeling clouds and radiation for the November 1997 period of SHEBA using a column climate model, J. Geophys. Res., 104, 6661-6678, 1999.

Rockel, B., E. Raschke, and B. Weyers, A parameterization of broad band radiative transfer properties of water ice, and mixed clouds, Contrib. Atmos. Phys., 64, 1-12, 1991.

Sassen, K., The polarization lidar technique for cloud research: A review and current assessment, Bull. Am. Meteorol. Soc., 72, 18481866, 1991. 
Sekhon, R. S., and R. C. Srivastava, Snow size spectra and radar reflectivity, J. Atmos. Sci., 27, 299-307, 1970.

Tao, X., J. E. Walsh, and W. L. Chapman, An assessment of global climate model simulations of Arctic air temperatures, J. Clim., 9 , 1060-1076, 1996.

Tiedke, M., Representing clouds in large-scale models, Mon. Weather Rev., 121, 3040-3061, 1993

Walsh, J. E., and W. L. Chapman, Arctic cloud-radiation-temperature associations in observational data and atmospheric reanalyses, J. Clim., 11, 3030-3045, 1998.

E. L Andreas, U.S. Army Cold Regions Research and Engineering Laboratory, 72 Lyme Road, Hanover, NH 03755. (eandreas @crrel.usace.army.mil)
J. A. Beesley, Department of Atmospheric Sciences, University of Illinois, 105 S. Gregory Street, Urbana, IL 61801. (tonyb @atmos.uiuc.edu)

C. S. Bretherton, Department of Atmospheric Sciences, University of Washington, Seattle, WA 98195. (breth@atmos.washington.edu)

J. M. Intrieri and T. A. Uttal, Environmental Technology Laboratory, NOAA, 325 Broadway, Boulder, CO 80302. (tuttal@etl. noaa.gov)

C. Jakob, European Centre for Medium-Range Weather Forecasts, Reading, RG2 9AX England, U.K.

(Received June 11, 1999; revised January 24, 2000; accepted January 29, 2000.) 
